\title{
Internet-Assisted Language Teaching: The Internet as a Tool for Personalised Language Exploration
}

\author{
Catherine Kanellopoulou, Andreas Giannakoulopoulos \\ Department of Audio and Visual Arts, Ionian University, Corfu, Greece \\ Email: catherine.kanellopoulou@gmail.com, agiannak@ionio.gr
}

How to cite this paper: Kanellopoulou, C., \& Giannakoulopoulos, A. (2021). InternetAssisted Language Teaching: The Internet as a Tool for Personalised Language Exploration. Creative Education, 12, 625-646. https://doi.org/10.4236/ce.2021.123043

Received: February 18, 2020

Accepted: March 22, 2021

Published: March 25, 2021

Copyright ( 2021 by author(s) and Scientific Research Publishing Inc. This work is licensed under the Creative Commons Attribution International License (CC BY 4.0).

http://creativecommons.org/licenses/by/4.0/

\section{(c) (i) Open Access}

\begin{abstract}
Over the last decades, the role of the teacher has changed due to developments in technology. Teachers now mainly provide direction and facilitate learning rather than being the know-it-all master. Their new role in the Net generation inevitably involves the use of multimedia Internet. Internet-based environments are student-centered and allow learners to be actively involved in the learning process. This paper presents how internet tools have developed over the years, with a focus on language skills development. It also discusses the basic principles behind building new personalised internet tools and presents examples from a specific experimental platform, which is part of a $\mathrm{PhD}$ study on foreign vocabulary learning. This platform makes use of a novel internet-based dubbing application called Film L2 Dubbing Activity (FL2DA). Our main aim is to discuss empirical data and shed some more light on how the internet-based environment and the use of feature film clips may assist in foreign language skills development and what is entailed in managing such an internet-assisted environment.
\end{abstract}

\section{Keywords}

Internet-Assisted Environment, Personalised Learning Tools, Foreign Language Skills Development, Multimedia Teaching, Internet-Based Learning, Internet-Assisted Classroom Management

As the Internet is constantly growing in popularity and availability, people around the world use it on a daily basis, often without even realising it. The Internet has been reshaping many aspects of society from advertising and marketing to sales and education (Warschauer et al., 2000). Language teachers who are looking for innovative methods of teaching have become increasingly interested 
in incorporating the Internet into their teaching plans. Recent developments in ICT support diversity in learning methods and multimedia and the vast amount of information linked by hypertext on the Web is invaluable, especially for self regulated learners. Learners are given the freedom and, in fact, they are encouraged to "manage the learning process independently and to explore linked pieces of information non-sequentially on the basis of their personal preferences and needs" (Son, 1998: p. 121). It is the first time that a teaching tool can so effectively personalise the materials to the level of the individual learner. This innovation is not to be taken lightly, as it is similar to personalising medicines for a particular patient. In education, this level of personalisation leads to self empowerment and autonomy in learning (Warschauer et al., 1996), which is the ultimate goal of teaching.

As educators, therefore, we never cease to look for new techniques and tools that will make our students more independent and gain as much as possible from their learning sessions. This quest was the basic motive for this PhD study of which this paper is a part. Except for presenting the basic principles of building effective online materials, the study combines the use of online learning tools with digital art in the form of the most popular daily entertainment activity worldwide, that of watching feature films. Films are commonly acknowledged to help learners improve their foreign language skills and vocabulary. However, there is still a lot of ground for research as to which is the most effective way of their exploitation. In this paper we present how internet tools have developed and a new internet-based tool using a feature film clip. Furthermore, we feel that presenting a novel tool should be accompanied by the basic conditions for its implementation in the online environment of the modern language classroom, which we introduce at the end of this paper.

\section{The Internet as a Teaching Tool}

Recently, the role of the teacher has changed and focuses mainly on providing direction and facilitating learning rather than playing the know-it-all master. As technology has become more prevalent in educational institutions, it is time to approach teaching and learning from a technological point of view. This inevitably involves the use of multimedia, such as animation, slideshows, announcements, blogging and even instant messaging, and the transfer of course content over the Internet. Interactive video research has given some very favourable results about multimedia effectiveness in language teaching. In his study on interactive video for Spanish teaching, Verano (1989) found that the more interactive the video work was, the more students retained. Liu (1993) concluded that computer-based hypermedia enhanced vocabulary learning, whereas other studies found that participants were more motivated when using interactive video discs (DeFelix et al., 1990) and enjoyed multimedia educational programmes (Borges, 2014; White et al., 2000). Truly interactive multimedia, which uses the Internet as its transfer mechanism, should be a consideration when designing an effective and dynamic classroom experience (Brett, 1996; Tucker \& Courts, 
2010). The Internet is a tool for creating an environment where authentic and creative communication can co-exist. It can create a virtual world that is very similar to the real world.

Sayers (1993) summarised the main contributions of network-based technology in the following elements: Motivation, Authentic materials for study, Independence from a single type of information source, Experiential Learning, Enhanced student achievement, Greater Interaction, Global Understanding and Individualisation.

When building teaching materials, the Internet is an extremely powerful ally. Instructors can access the Internet for resources, teaching materials and ideas in general, as well as share their knowledge with other professionals. The Internet is a great tool for teachers to create their own internet space, for example e-class webpages, blogs, online learning games, chat rooms, etc. They can build and upload materials for their students to access at their own leisure (Meagher, 1995; Warschauer et al., 2000); or create forums for their students to exchange ideas, discuss problems of any kind and so on. Furthermore, in situations where it is impossible to bring part or all of the class physically together, lessons may also be held online. A case in point is the recent pandemic situation (2020-2021) where classes worldwide were held online at all levels of education. Without online conferencing applications, this would have been impossible and the choice between closing down educational institutions altogether or allowing them to continue to operate despite the risk of spreading the virus infection would have been an impossible one to make. In short, teachers can use the Internet to motivate their students (Muehleisen, 1997) whereas students can use the language they are studying outside the classroom, making the language part of their daily lives. Another invaluable feature that the Internet holds for foreign language learners is potential communication with native speakers of a language based anywhere in the world. Access to real life communication with native speakers of any variety of the language, including different accents or dialects, whether in oral or written form, would be virtually impossible without the Internet (Warschauer \& Kern, 2000). Learners can communicate on a one-to-one, as well as one-to-many, basis from home, school or any place they choose.

The Internet is a dynamic medium which can provide a wealth of information in several modes. Foreign language instructors should be encouraged to experiment with the Internet so they can fully exploit the possibilities for language learning using this resource that opens pathways to authentic materials and dynamic communications with native speakers around the world (Lee, 2008). It can equip teachers with teaching tools, as well as provide them with immediate answers to questions or problems they might come across while teaching or preparing their teaching materials. Students have access to information and resources by simply clicking on a mouse button, provided they just have a computer or even a smartphone with an internet connection. Most of the times, the information is presented in meaningful contexts which may be explored either widely or specifically. Furthermore, its use can be interactive and collaborative in 
nature. A virtual community of learners may now exchange knowledge, ideas and perspectives via e-mails, conferencing platforms, chat rooms, blogs, vlogs, newsgroups, etc.

Turning to the development of specific language skills, until recently, the tools available through the Internet focused on listening and speaking activities but there has been a gradual and increasing emphasis on reading and writing. Oral activities for improving communication skills can be simulations, role-plays and online discussions, to name a few. Computer simulations provide a stimulus for skills development, by offering both a focus for oral activity and different scenarios for learners to talk about. In addition, as grammar and vocabulary need to be taught in meaningful contexts, the Internet provides a platform with such possibility. Over time, students are given the opportunity to use the language they have learnt in authentic context. Especially regarding English as a foreign language, and given the global spread it has achieved covering about $85 \%$ of all stored information in the world (Crystal, 2003), the choice of materials is endless.

Warschauer (1996) suggests that teachers should think about the implications of using the Internet for their classes because its use has become so widespread both among teachers, as well as students. It would, therefore, be extremely beneficial for teachers to learn how to use Internet tools effectively with the support and encouragement from their teaching situations (Warschauer et al., 2000). In other words, teachers need to gain knowledge and develop the necessary skills to use the Internet in order to maximise their on-line teaching capabilities and effectiveness.

Overall, the enormous potential of the Internet has gained considerable attention in internet-assisted language teaching, nevertheless, there is greater need for a solid background of research (Celik, 2013) since most of the available research focuses on teachers' and students' perceptions of its use (Dashtestani, 2014; Mollaei, 2013; Radovanović \& Kraguljac, 2017; Rezaie \& Sayadian, 2015; Shin \& Son, 2007; Yükselir, 2016) and not so much research provides quantitative data on specific language skills development using specially made internet tools. It is a fact that the use of internet-assisted technologies come mainly with positive assessments; however, the quality of the tools and their utilisation varies and needs to be improved via professional development programs for internet-assisted language instruction (Celik, 2013).

\section{The Internet-Assisted Environment}

Internet tools create environments that allow learners to be actively involved in the learning process. In other words, these environments are student-centered since they provide individuals with opportunities to learn different ways of obtaining information, and constructing their own knowledge by interpreting and evaluating the information they have acquired (Diana \& Schaik, 1993).

Internet television, web pages, wikis, blogs, podcasts, search engines, forums, news groups, e-mail, online games, on-line streaming, simulations, audio, music 
and video-sharing sites, web-based software, and other internet-based tools and environments are now recognised as educational tools to be used in the teaching of foreign languages, literature and cultures (Arikan, 2008). Among the multitude of the applications that constitute our internet-assisted environment, we would like to focus on two applications that are the basis of the experimental platform we created for the $\mathrm{PhD}$ thesis this paper is a part of.

\subsection{Video on the Internet}

There are many applications that would benefit from a reliable and fast system of video data over the Internet, not only for the obvious purposes of entertainment, but for many other applications such as multimedia presentations, video conferencing, remote learning, video archives and libraries, etc. Interactive video games where the user or player can choose the outcome from a number of possible scenarios are one area currently being integrated in the curriculum schools in the USA. Such applications may well be the answer to the problem educators have had trying to figure out a way to compete for student's attention.

Personal communications applications such as video conferencing, video storage for viewing video later and multimedia email that allow the sending of electronic mail with attachments of video are additional methods which can be used to enhance student learning. There are database services and archives which call up video clips from a library or archive in the same way a user might get a file or book from a library. There is great variety of how to use internet videos in the classroom. A quick search on youtube.com, for example, could result in thousands of possible useful videos. Classroom instructors need to find creative ways to integrate such videos into their once static lectures. Imagine a biology teacher demonstrating how a cell works and presenting this on video or posting it on YouTube for her students to view. There are countless methods of effectively integrating multimedia applications into the classroom. Today, instructors are limited more by their imagination and creativity than by accessibility of technology.

\subsection{Streaming}

The process of playing an audio or video file while it is still downloading is known as streaming. The advantage of streaming multimedia files is that you no longer need to wait for an entire file to download before you can listen to it or watch it. In the framework of this new technology, the multimedia file resides on the host server and is not downloaded to the client computer. The advantages of streaming include faster playback, smaller file size, easy updating because the file is only on one server and flexible playback as the file can be stopped and started on demand. Although it is possible to stream some multimedia files without the need to encode them into a special format, it is usually more efficient to put them into a format which was designed for streaming.

The biggest issues of streaming lie with the dependence upon a good internet 
connection and speed. In the case of video streaming (watching the video in realtime, without downloading it first), one should keep in mind that the buffering process (downloading the file to one's computer) during playback of the file influences the quality of the playback significantly, and in case of slower connections this can put the language activity at risk.

As might be expected, the most popular forms of multimedia streaming on the Internet are films and live sporting events. Users can listen to a radio broadcast of any game or watch a film or sports game over the Internet from anywhere in the world. The games and films are archived and made available for playback later. These archives can be streamed and allow a user to start and stop a broadcast or film as one pleases. The actual archived files are only kept on servers and can be streamed on demand to users.

This same concept can be utilised in the classroom to allow student access to classroom material around the globe. Provided that copyright restrictions are respected, downloadable video files can also be incorporated in self-study packages for a number of learning objectives. A teacher, for example, may prepare listening comprehension activities, such as quizzes, multiple choice questions, etc. The most flexible instructional uses can be made with downloadable video files, which can be saved locally before the lesson and played off-line, so that a slow internet connection or poor buffering cannot influence the quality of the videos.

At the current rate of growth, about half of the world's population will probably be online by the end of this decade. Never in the history of civilisation have we seen a new technology adopted by so many, in so many different places, in such a short period of time (Leu et al., 2011). The advent of the Internet has resulted in a rapid, continuous technological change which has had a direct effect on the nature of literacy. The Internet has delivered new technologies that require novel, different skills to read, write, and communicate effectively. To be literate today often means being able to use some combination of blogs, wikis, texting, search engines, Facebook, Zoom, Google Docs, Skype, Chrome, iMovie, Contribute, Basecamp, or many other relatively new technologies, including thousands of mobile applications, or "apps" (Leu et al., 2011). To be literate in the future will be determined by even newer technologies.

\section{Internet-Assisted Language Skills Development}

A main concern when building internet-assisted materials is the investigation of ways to teach specific language skills, both receptive (listening and reading) and productive (speaking and writing). For the purpose of this $\mathrm{PhD}$ thesis, we focused on internet-assisted development of receptive skills, along with the development of learners' pronunciation and the acquisition and long-term retention of new vocabulary. Broadly speaking, we also consider pronunciation as a language skill (Prodanovska, 2017) which can benefit greatly from the development of oral productive skills using online tools. The same is true for vocabulary de- 
velopment (Lin \& Siyanova-Chanturia, 2014). When building internet-assisted materials to facilitate the foreign language classroom, it is assumed that some part of the lesson will be conducted in the Web environment, but it should be stressed that, when structuring the teaching process, the online services, tools and website materials to be used in the classroom should play an auxiliary role to the teacher.

The incorporation of the Internet into teaching foreign language skills is not only a medium for conducting classroom instruction, but also for out-of-class individual work and materials development as well as lesson preparation. We choose to present the specific skills relevant to this particular study platform with examples.

\subsection{Internet-Assisted Reading Skills Development}

It also seems obvious to say that the Internet should be used for practising reading skills, since most of the Internet content is text, and whatever students do online, there is always a strong element of reading practice. The Internet is a vast resource of varied, interesting material on many different levels of language and it is only up to teachers to make use of it for the benefit of their students. Thus, there has been extensive research on understanding the nature of hypermedia literacy. It seems that thanks to the richness of textual, visual and audio input, the execution of the pre-stage reading sessions can be largely facilitated. Similarly, the post-stage sessions, with their productive character, can be also enhanced by skilful introduction of the electronic media. Another important aspect that needs to be elaborated upon here to present the rationale for the introduction of online reading is the possibility to incorporate various resources to assist comprehension. Looking up active dictionary pages, glossing selected works, hyperlinking a reading text to a corpus, all promote active learning and contextual guessing, which are so crucial in developing literacy. Admittedly, the Internet material is not made specifically for a given class, but the problem of an overly difficult reading content, though certainly crucial, may be overcome by varying the difficulty of the task and the amount of teacher control. If a website's language is rather demanding, the teacher should simplify the reading task; for example, instead of asking students to read the whole text and summarise it, the task could be to find specific details such as names or dates. The type of website plays another role here, as the language might be difficult but be accompanied by graphics, illustrations or pictures, which students will certainly find easier to process. Finally, the teacher may provide more support if the linguistic level is beyond her students' capacity, and may even translate for students if that is the need. In general, the principle of grading the task rather than the text should be respected, and teachers should make as much effort as possible to find alternative materials (of easier language level, with more graphic input and less cognitive load) and create tasks accordingly.

Using the Internet for teaching reading skills can facilitate the teaching process in a variety of areas. One of the most important elements is students' 
exposure to readily available authentic materials. Other key elements include swift information exchange in the classroom and the ease with which students familiarise themselves with online reference tools. Since the Internet is predominantly composed of text, every single activity students do in any Internet-assisted lesson will involve reading. This fact alone, of course, may not help students develop particular reading skills so it rests upon the teacher to organise tasks to facilitate this. Reading skills such as scanning, skimming, reading for gist, or reading for details can easily be developed with the use of the online texts available. The clear advantages of the Internet as a digital coursebook include reading materials that are authentic, constantly updated and interactive. Furthermore, there are endless novel texts which offer a vast choice of themes, language levels, cultural backgrounds etc. All of these justify internet-based reading instruction to students, encouraging them to benefit from extensive reading of online materials with the use of tools and strategies they have been exposed to in class. Online reading activities may include reading the content of the site and answering questions about it or completing a specially prepared quiz (reading for gist or specific information); reading the instructions given in the site and then executing them in the classroom (reading comprehension); finding specific information about an issue (reading for details) etc.

Another consideration of internet-assisted reading which was incorporated into this thesis's experimental platform is the feature of glossing. Glossing, or word annotation of texts, in the form of providing vocabulary explanations either in the students' L1 or in the L2 in the form of synonyms/antonyms, or even giving example sentences, etc., which aids text comprehension (Anderson, 1998). The ease and immediacy of this feature would be impossible to achieve without internet technology. In practice, texts can be glossed with the aid of a word processing or other programme. Glossing may include inserting (Krajka, 2003):

a) Annotations which give students glosses of difficult or new words;

b) Voice comments, such as voice hints, recorded synonyms or antonyms for the students to listen to while reading the text;

c) Audio files, either recorded by the teacher or other external files, which can be hints for students on which word to use;

d) A picture which can be the explanation of or a hint for the word in questions;

e) A hyperlink to reference sources on the Internet, so that students can instantly consult a dictionary, a grammar compendium or an encyclopaedia.

Perhaps the most prominent advantage of internet-assisted glossing, as opposed to simple word-processor glossing, is that glosses are not visible all the time and enables the teacher to provide selected lexical items with glosses in the form of hyperlinks, which can be activated by a learner if needed. This feature enhances students' self-regulation, since learners decide whether or not to use optional vocabulary help to assist comprehension. Furthermore, this type of meaning processing of a reading text in a computer-mediated context does not distract students from the original text as doubleclicking any word or phrase on 
the page provides a pop-up window with the definition of the word opened on top of the original text as a separate window. The main consideration for teachers and internet-assisted development of reading skills rests with the optimum balance between reading comprehension, Web searching and website evaluation.

The experimental platform we created for this thesis included three of the above mentioned annotations, namely, annotation of lexical items single words or phrases with their meanings, in either L1 and/or L2 (depending on the participant's linguistic level), adding hyperlinks to an online dictionary and audio files for clarification of the pronunciation of specific words or phrases (Figures 1-3). The administrator recorded which of these features each participant used and statistical analysis followed, also taking into consideration the participants' motivational profiles.

A final comment regarding the development of reading skills with the use of the Internet in class lies within the Communicative Approach framework. It is essential that in order to achieve and maintain students' engagement, the activities compiled for the class should be constructed in such a way that learners have

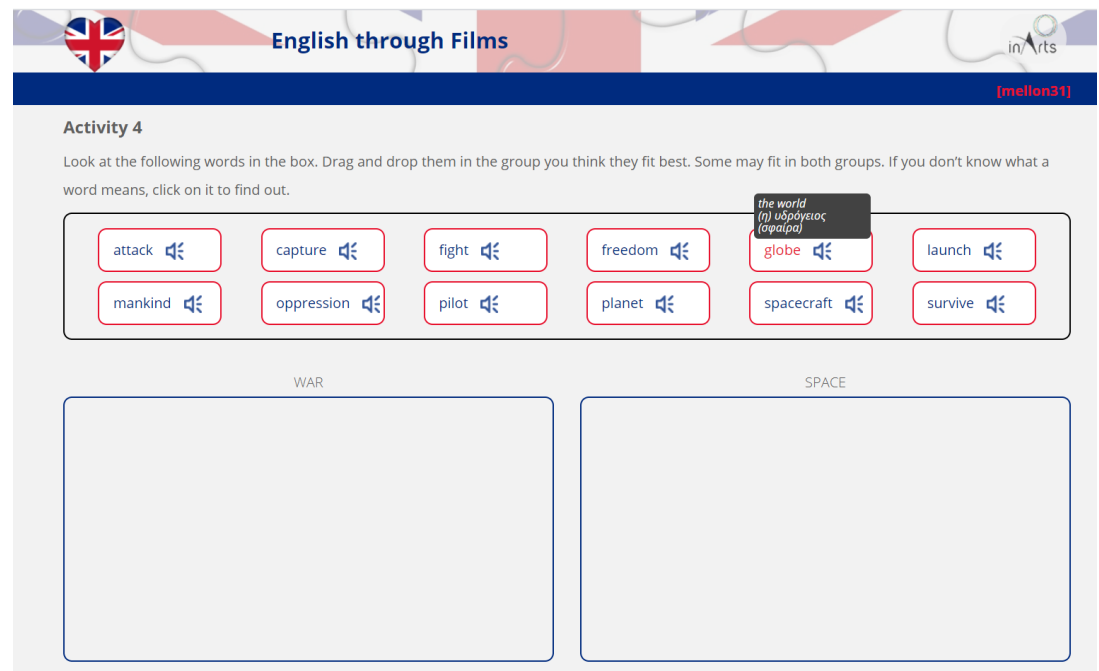

Figure 1. Glossing of "globe" with L2 and L1 equivalents, activated by the user.

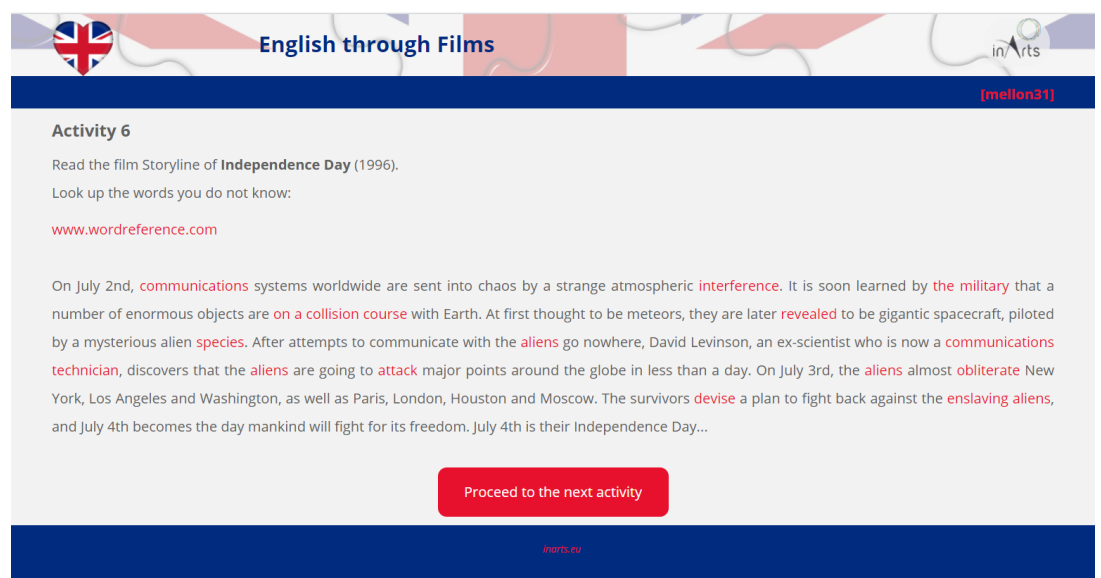

Figure 2. Webpage of text with hyperlinks on selected lexical items. 


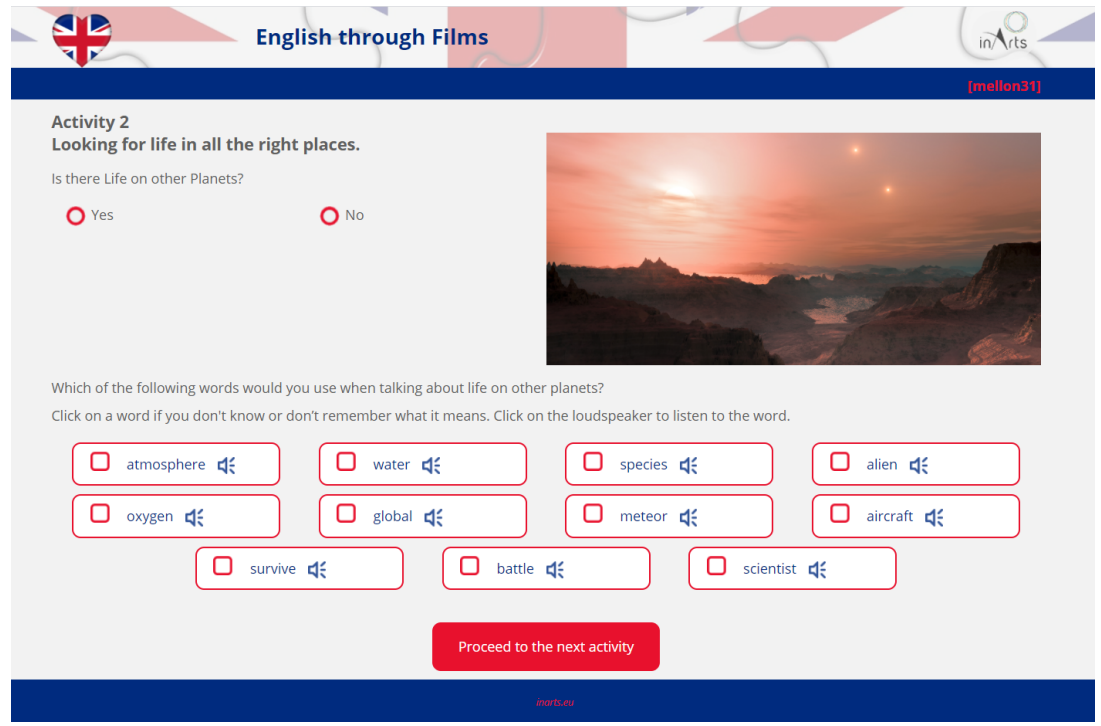

Figure 3. Webpage of the experimental platform with the loudspeaker feature.

a true communicative desire and purpose to use the language, with "greater focus on content and meaning than form and grammar preferably with choice of language rather than restricted to use specific language structures, designing language tasks to create information, opinion or reasoning gap" (Krajka, 2007). Ideally, students should depend on each other for their information and interact to accomplish a given task, working on reading the text, hearing the text, mastering new vocabulary, paraphrasing and interacting at all stages of the activity.

\subsection{Internet-Assisted Pronunciation Skills Development}

One of the most prominent characteristics in the speech of a foreign language is its phonological system. Nowadays, the increasing demand for global competence and international communication requires increased proficiency in a foreign language and this proficiency does not merely refer to vocabulary acquisition or grammar competence, but good pronunciation as well.

The development of pronunciation skills is a prerequisite for appropriate oral production and interaction, because a learner's comprehensible speech is the key for effective communication. The advent of digital audio in the foreign language classroom has given teachers a great tool for the development of pronunciations skills. Some of the features of digital audio include variable playback speeds, random access to sound files, recording and storing students' oral production, and so on.

Internet sites with various audio materials, online Text-to-Speech (TTS) software, and readymade or teacher-prepared audio exercises contribute to the development of pronunciation awareness and skills. The most usual teaching procedure in mainstream language education when preparing pronunciation practice materials starts with the discrimination and articulation of individual sounds, moves on to longer and more complicated phrases, and with the practice of communicative exercises or dialogues aims at language production in discourse (Krajka, 2007). 
Perhaps the most revolutionary tool that digital audio has provided foreign language teachers with is the TTS. Among other advantages, the TTS and synthesized speech affords us the possibility to manipulate all speech variables, increased students' exposure to a variety of accents and the customisation of tasks to different kinds of text difficulty. Digital audio can be conveniently searched for, retrieved, manipulated, stored and played, provided that the copyright restrictions are adhered to (Sobkowiak, 2003).

Some of the most useful applications of TTS in CALL include talking dictionaries, talking texts reading aloud any section of text (a single word, a sentence, a paragraph, etc.) typed or copied into it; pronunciation practice of individual or combined phonemes or intonation; and dialogue creation, with the synthesised speech replacing a dialogue partner (Handley \& Hamel, 2005).

Exposing students to the sounds of the target language, in isolation and in context, in various positions within a word, is essential in developing discrimination skills. The existence of new sounds in the target language, as well as the sounds that are substantially different in quality and/or quantity, needs to be demonstrated to students in carefully built exercises that train them in noticing new sounds, which eventually grow in complexity from simple isolated sounds to more complicated sounds in words and phrases.

The use of online audio resources to help prepare materials for the discrimination of sounds is not to be underestimated. Free availability of a variety of audio files, both downloadable as .mp3 or .wav (podcasts) and streaming, creates favourable conditions for exposing students to the target language speech in its natural form. It is advisable, however, to collect audio resources where particular sounds are prominently featured before exposing students to the authentic flow of connected fast speech accompanied by background noises (e.g., announcements in train stations).

The selection of lexical items for pronunciation work, whether aiming at simple sound discrimination or pronunciation practice, is a task that teachers should approach cautiously. Ideally, the words that students work with should be of the appropriate language level, including both the lexical items that they have already been exposed to receptively, and those that constitute their productive lexicon, while random selection is minimised. Similarly, the choice of words and phrases needs to focus on the sounds in question in various positions, both in monosyllabic and multisyllabic words (Krajka, 2007).

Some of the techniques for improving sound discrimination include: minimal pairs (where students distinguish the same or different sounds), odd word out (where students find the word with a different sound from a given set of words), matching words or sounds with pictures, etc. The practice phase of pronunciation instruction takes learners from discrimination and presentation to the production of new sounds.

In the post-test of the experiment for this thesis, activity 2 (Figure 4) was compiled with the technique of minimal pairs where participants had to tick the correct pronunciation of a word. The selected words had all been target words of 


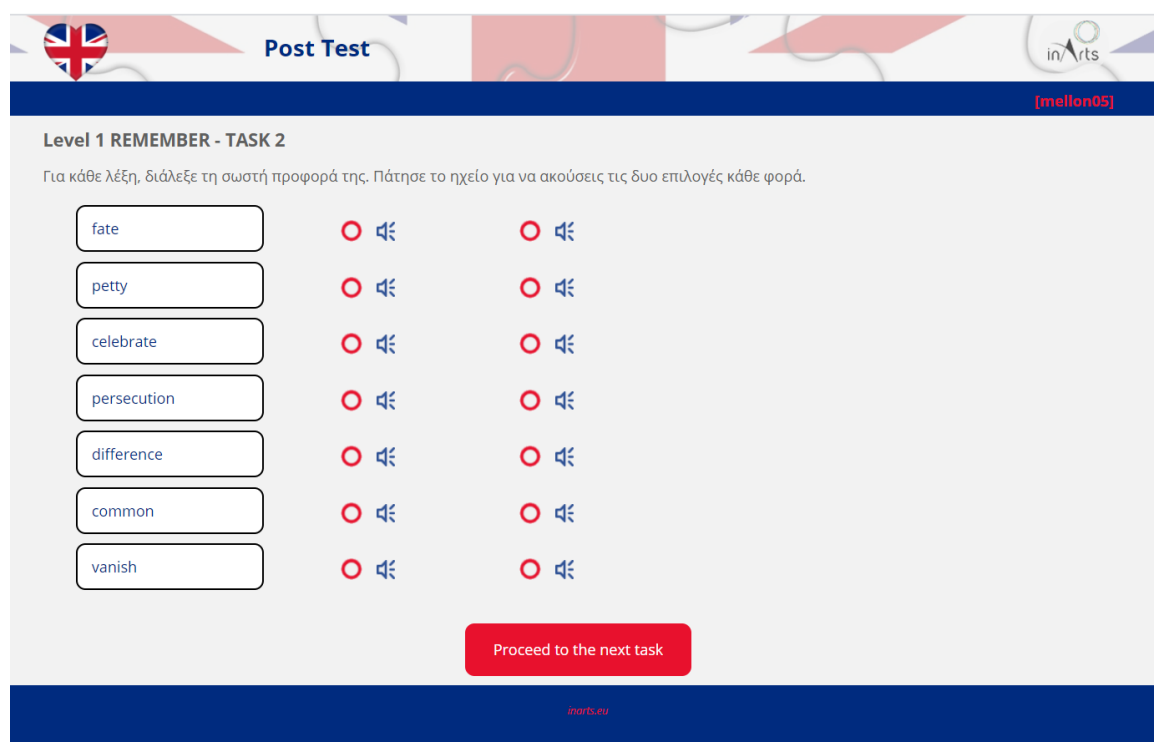

Figure 4. Pronunciation task with minimal pairs.

the pre-test activities accompanied by the audio file feature (participants could click on a loudspeaker to listen to the words).

\subsection{Internet Television in Vocabulary Acquisition Development}

Nowadays, researchers have begun to look into the use of multimedia in vocabulary development, its relationship with reading comprehension and how vocabulary acquisition can be enhanced with CALL; taking into consideration the principles of Multimedia Cognitive Theories and how they can be applied to teach foreign language vocabulary.

When teaching foreign language vocabulary there are linguistic, psycholinguistic, and sociolinguistic aspects of word knowledge, which include word frequency, vocabulary growth in native speakers, collocation, register, case relations, underlying forms, word association, and semantic structures (Richards, 1976). Richards's assumption about vocabulary knowledge is that native speakers continue to expand their vocabulary in adulthood, whereas there is little development of syntax in adult life. This is because for any language speaker, to "know" a lexical item entails more than just knowing its meaning. It also entails knowing the degree of probability of encountering that lexical item in speech or print, knowing the sort of other words most likely to be found associated with it, knowing the limitations imposed on its use according to variations of function and situation, its syntactic behaviour, its derivations, its semantic value, other meanings associated with it, and more. However, the sheer vocabulary size of a learner is a good indicator of overall linguistic performance (Carter \& Nunan, 2001; Harley, 1996; Wilkins, 1972), as it is important for fluency in speech and learners associate their progress in language learning with an increase in the number of words they "know". Another distinction that is frequently made in literature is that of vocabulary breadth (how many words you know) and vocabulary depth (how well you know them). The notion of degrees of word knowledge 
from vague to precise is a deep seated one in vocabulary studies (Read, 2004). Finally, another factor of word knowledge is the ability of the speaker to use it freely when the situation requires it. In this respect, there are three stages of knowledge: its basic receptive or passive knowledge, its controlled productive knowledge (i.e. when prompted by an exercise or any kind of activity), and free productive knowledge, for example in free speech or composition writing. No matter how we approach the issue of vocabulary learning, the first and second stages in L2 vocabulary acquisition are to encounter new vocabulary items and then access their meaning.

Vocabulary knowledge in foreign language acquisition has long been neglected, as the study of foreign language grammar, syntax and phonology have been more dominant in the past; however, it has recently been receiving increased attention in the language teaching curriculum. As Laufer \& Shmueli (1997: p. 147) point out, "vocabulary is no longer a victim of discrimination in second language learning research, or in language teaching". According to Carter and Nunan (2001), this redirection of focus may be attributed to several factors "such as the influence of comprehension-based approaches to language development, the research efforts of applied linguists, and the exciting possibilities opened-up by the development of computer-based language corpora". There is no question that vocabulary acquisition is essential to foreign language acquisition and academic achievement and "is vital to reading comprehension and proficiency, to which it is closely linked" (Tozcu \& Coady, 2004). Limited vocabulary is a major obstacle in foreign language learning and its effective use.

Advocates of vocabulary acquisition and development as a primary concern in foreign language learning believe that vocabulary requirements in every stage of the language learning process are most of the time greater than the requirements for grammatical rules (Hatch \& Brown, 1995). It has also been recorded that when people are in a hurry or need to get a message across quickly, they increase their use of vocabulary to convey messages and reduce grammar (Jordens \& Lalleman, 2010). Research on computer-assisted vocabulary learning should take vocabulary skills development into serious consideration for both intentional and incidental learning. This has significant implications for CALL software design such as "the presentation methods of on-line lexical resources and the effective use of verbal and visual information in reading instruction" (Shokrpour et al., 2019). So far, some studies regarding the effectiveness of electronic methods in vocabulary acquisition have come up with inconclusive results (Kaya, 2006; Son, 2001); however, a great number of studies involving multimedia applications for vocabulary learning with the use of different types of annotations indicate this method helps the learning and retention of new foreign words (Akbulut, 2007; Yoshii \& Flaitz, 2002) and a close relationship between vocabulary and reading comprehension. More studies involving CALL applications also conclude that the use of computer assisted vocabulary instruction have significant positive effects on vocabulary acquisition and retention (Barani, 2013; Eizadpanah et al., 2014; Khoshnoud \& Karbalaei, 2015; Talarposhti \& Pourgha- 
rib, 2014).

Because of those findings, researchers and educators have been trying to develop CALL applications that will effectively support learners in the domain of foreign language vocabulary acquisition and retention and many have now started to focus on internet-assisted vocabulary learning and skills development as a step further than simple CALL. Easy access to the Internet has given teachers and learners an amazing tool at their fingertips. The Web allows instant access to a vast array of resources and up-to-date information that can be exploited for foreign language vocabulary development. Some of the supplementary language activities that could be incorporated in the classroom are online reading tests and comprehension questions, interactive grammar exercises with immediate feedback, video and pronunciation exercises, online vocabulary tests, films, online TV and so forth. However, for the scope of this paper, we would like to focus on internet television and film streaming as tools for foreign vocabulary learning.

Internet television is different from other outside-the-classroom L2 learning activities. It is likely to appeal to learners from all proficiency and motivation levels because even learners with low L2 proficiency and low motivation to learn English enjoy watching films or TV serials; after all, those are part of most people's daily entertaining. With all the images, sound effects and subtitles, the content of films or programmes on internet television are easier to comprehend than content without images, sounds and/or subtitles, for example while listening to the radio or reading novels.

Conventional television and watching films are so commonplace in our everyday life that it is likely learners will readily accept internet television and film streaming. Internet television facilitates contextual vocabulary acquisition as most vocabulary is learned naturally from context rather than through explicit vocabulary instruction. Learning vocabulary within context is key to successful vocabulary acquisition (Sternberg, 1987). Naturally, there is not enough classroom time to teach the thousands of words necessary for comprehension of novels or newspapers; nevertheless, L2 learning courses need to find ways to help their learners reach this language learning target. When compared to reading, TV programmes offer more low-frequency words which are encountered repeatedly in a relatively small amount of viewing time (Webb \& Rodgers, 2009), this is especially so in the case of episodes from the same TV series. It appears that when a word occurs more frequently, it is more likely to be noticed and to become familiar (Peters \& Webb, 2018). It makes sense then to propose extensive TV viewing inside and outside the classroom as a teaching method. Regardless of their backgrounds, learners can enhance their L2 proficiency through extensive exposure to internet television. Some of the most prominent gains are "their increasingly fluent speech, more native-like accent and a growing repertoire of useful expressions for informal social contexts" (Lin \& Siyanova-Chanturia, 2014).

However, there are some important points to keep in mind. First and fore- 
most, the learners need to pay attention to the language use while enjoying their favourite film or serial. Television serials may hold an advantage here, as repeated viewing of episodes or scenes is a common strategy that can promote attention to specific language. However, research has not reached a conclusion as to how many viewings would be enough for successful vocabulary acquisition. In Lin and Siyanova-Chanturia's (2014) study, one of the participants watched some scenes so many times that she had subconsciously internalised the lines and the characters' intonation. This is invaluable for pronunciation and intonation acquisition, but when combined with the plot of the story learners experience language "hands on", as if they are participating in a theatrical production and they identify with one or more of the characters in a play. It is recommended, of course, that learners keep a balance between the number of new and repeated episodes, so that they are equally exposed to new language, as well as repeat whatever language they have already come across.

Another consideration is whether learners possess the necessary skills for implicit vocabulary learning. In most foreign language classrooms to date, most learners may be accustomed to receiving explicit instructions and close supervision. Learners may need training on contextual vocabulary learning skills to assist them in learning implicitly from internet television programmes. Needless to say, that this is a skill all learners would benefit from while studying a foreign language, but it is even more valuable for watching television programmes. Instructors should therefore equip their classes with such techniques, so that learners get the best out of their viewings.

Furthermore, there are certain strategies for the enhancement of the effectiveness and efficiency of internet television in language acquisition and, more specifically, vocabulary learning. As motivation is of paramount importance in such activities, personal preferences should take priority in programme selection. However, programmes should reflect real language in everyday use, or at least within authentic settings. According to Lin's (2014) study of foreign language vocabulary in 11 genres of internet television programmes, "factual, drama and comedy categories were more representative of everyday English than those in music, learning and religion categories" (Lin \& Siyanova-Chanturia, 2014: p. 6). Therefore, these programmes should take priority when recommending internet programmes to learners. Narrow viewing (targeting programmes of similar nature) is also recommended because learners gradually develop background knowledge that aids comprehension of the content. Acquiring lexical items is more likely when learners are exposed to recurrent language within programmes of the same genre (Schmitt \& Carter, 2000). Finally, learners may experiment with subtitles, as these are almost always available on internet television programmes. Depending on their level, learners may choose from L1, L2 or no subtitles for different viewing experiences and language skills development.

In conclusion, the Internet and more specifically internet television and streaming technology offer a myriad of programmes to choose from when learning a foreign language. It rests upon both the learners and the language instructors to careful- 
ly and systematically exploit this medium as a supplementary resource in a foreign language learning course.

\section{Managing an Internet-Assisted Classroom}

The Internet has brought about a revolution in how we collect, store and share information. Even elementary age children know how to upload videos on YouTube and TikTok, send messages on Twitter and download music from a multitude of website. College students use e-class sites as well as social networking sites to share lecture notes or homework problems. The traditional models of education in most countries are static and slow changing, but the availability of online resources allows us to consider a new model of education which serves students faster, more inexpensively and more efficiently than ever before. A quick search on a search engine can provide us with class syllabi from primary school to university level, lecture notes, homework problems (and answers), test questions, video lectures, and announcements all readily available for free. It seems that the advent of the Internet may also promote the dissemination of high-quality materials at almost no cost and contribute to levelling the field for those who until now have been underprivileged in terms of education.

A new culture that supports learning, sharing and the ownership of knowledge is emerging. The technology to support learning already exists as does the ability to bring this technology to the classroom (Tucker \& Courts, 2010). The challenge now is to find ways to use this technology to facilitate and enhance learning in the foreign language classroom. It seems that so far institutions that are already implementing technology in the classroom do not meet today's learners' expectations. PowerPoint slides and hyperlinks embedded in a course shell are already considered outdated (Tucker \& Courts, 2010). The Net Generation, that has never known a world without the Internet (Lorenzo \& Dziuban, 2006), is technically savvy, well adapted at communicating via the Internet, and because of internet technology and speed they are used to instant action. The traditional language class syllabus has been slow to adapt to the learning styles of these students.

Multimedia applications on the Internet are used to transfer information, or convey messages of any kind. These include instant messaging, slideshows, animation, podcasts and video simulations; anything that integrates sound, text, graphics, animation, or video. Multimedia has a positive influence on the learning outcome and by extension this enhances the effectiveness of the Internet as an educational platform. Given this, and the fact the technological developments never cease, integrating multimedia in the foreign language classroom is a necessity for the course design of the 21st century classroom. As the result of all the above, a new method has slowly emerged called "Project-based Multimedia Learning" (Simkins et al., 2002). This method combines Project-Based Learning with the use of Multimedia in class. Project-Based learning is an established educational method, while the introduction of multimedia in the classroom is a 
dynamic new form of communication. The merging of these two results in a powerful teaching strategy. However, implementing this strategy can be demanding, since it goes beyond the boundaries of the classroom and students are no longer confined to learning material from static sources such as text books or stagnant websites. Multimedia and the Internet allow students to experience a learning environment rich in knowledge and experiences.

Before discussing the dimensions of Project-Based Multimedia Learning and how to manage a class within this framework, it is imperative to present the core notion of the method, as it is often misunderstood. Project-Based Multimedia Learning is not simply using multimedia during class, but "... a method of teaching in which students acquire new knowledge and skills in the course of designing, planning, and producing a multimedia product' (Simkins et al., 2002).

Multimedia products could be technology-based presentations, such as a website, a video, a slide show, or even a TikTok recording. Another suggestion for a multimedia product is the Film L2 Dubbing Activity (FL2DA) which was part of the experimental online platform of the $\mathrm{PhD}$ thesis this paper comes from. This application taps into the students' creativity and need for artistic expression. It is a short feature film clip, where the user is asked to record his/her own voice over one of the actor's speech; a kind of "film karaoke". In our case, the film clip was from "Independence Day" (Emmerich \& Devlin, 1996) and participants were asked to dub the President's speech to air-force pilots before the decisive air-battle that would save humanity from annihilation (Figure 5).

The application had a playback feature so that the user could watch the film clip with their voice recording, accompanied by all the background noises and sound effects. The application involves role playing, which is one specific online activity that can contribute to a successful and highly enjoyable learning experience (Bender, 2011). One of the most striking aspects of role playing is the way that students relate education with experience, which is the optimal path to true learning (Dewey, 1986). Language instructors could use dubbing as a learning tool within the internet-based classroom framework, even with the limited

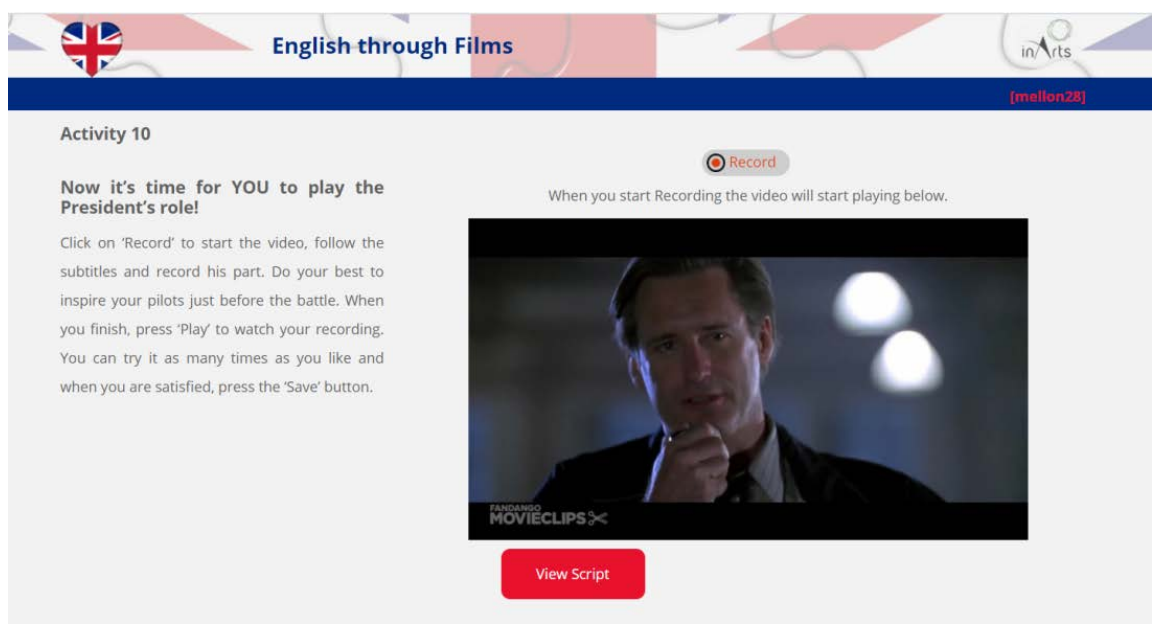

Figure 5. The FL2DA application online page. 
resources available. We need to keep in mind that researchers have recorded that even if students do not perceive much difference between their learning achievements in a multimedia class session compared to a traditional one, they view the teacher's effectiveness as higher in the multimedia classroom than the traditional one (Deng \& Zhang, 2007). Students tend to like using computers, even when they may not make much progress (Stenson et al., 1992).

\section{Conclusion}

Many foreign language professionals continue to focus on the traditional pedagogical teaching methods and the development of their specialised knowledge and teaching skills. While traditional teaching methods are essential as the framework of any lesson plan, effective teachers also need to create a classroom environment which facilitates learning. In today's foreign language classroom, that means integrating technology. Teachers and language instructors may use the Internet as a transferring mechanism and provide their students with multimedia rich content in order to create a dynamic classroom experience (Tucker \& Courts, 2010). In the case of feature films, as a start, we propose incorporating carefully selected film clips as study material. This would help motivate students, especially if the clip themes were close to the students' preferences. Alternatively, teachers might ask the students to propose clips or parts of feature films and select from those in order to create a multimedia product. They could prioritise the extracts according to their educational goal and ask the class to create products in line with the principles of Project-based Multimedia Learning. In the case of the FL2DA application, it could be used in a number of different ways, depending on the students' preferences and personalities, for example, students can do the recording at home and post it online as a fun activity; a group of students could dub different actors in the same clip and present it in class as a group activity; or even an Oscar-type competition could be organised for the whole class to participate in and decide on the winner. Understandably, this requires time-consuming preparation on the part of the teacher and in FL2DA clips are not available at the moment. In some cases, this limitation could be overcome by lowering the volume of the video. In other cases, the students themselves could come up with solutions like editing the video and removing the recording of the speakers. What is important, of course is to respect copyrights and use these exclusively for educational purposes (Fair Use). Despite the difficulties because of the absence of a databank with FL2DA clips, the activity is worth the effort as empirical results of this thesis indicate that the FL2DA treatment positively affects long-term vocabulary recall. Further research might reveal that it can also enhance learning outcomes in other foreign language learning areas.

Curriculum designers and lesson planners would greatly benefit from incorporating the internet multimedia learning dimensions to create new dynamic sessions which students would enjoy and engage in. The use of internet resources is a meaningful way to integrate language and culture. Foreign language 
teachers should experiment with the Internet to take advantage of the possibilities and it offers for language learning by making use of authentic materials and dynamic communications with native speakers around the world (Lee, 2008). What is most clear from extensive research is that students tend to enjoy using computers and the Internet and "future developments in networked communication, multimedia, and artificial intelligence will likely converge, creating a potentially more central role for the computer as a tool for authentic language exploration and use in the second language classroom" (Warschauer \& Healey, 1998).

Classrooms today are changing and infrastructure is now available with respect to computer hardware as well as internet access. It is imperative that internet multimedia technology is incorporated into the foreign language curriculum since it encourages students to use text, images, sound and animation in their assignments and helps them develop the necessary skills for foreign language communication in the new technologically demanding world.

\section{Conflicts of Interest}

The authors declare no conflicts of interest regarding the publication of this paper.

\section{References}

Akbulut, Y. (2007). Effects of Multimedia Annotations on Incidental Vocabulary Learning and Reading Comprehension of Advanced Learners of English as a Foreign Language. Instructional Science, 35, 499-517. https://doi.org/10.1007/s11251-007-9016-7

Anderson, L. (1998). To Gloss or Not to Gloss: An Investigation of Reading Comprehension Online. Language Learning \& Technology, 1, 41-50.

Arikan, A. (2008). Using Internet Groups in the Learning of Literature. Hacettepe Üniversitesi Eğitim Fakültesi Dergisi, 34, 19-26.

Barani, G. (2013). The Impact of Computer Assisted Language Learning (CALL) on Vocabulary Achievement of Iranian University Students EFL Learners. International Journal of Basic Sciences \& Applied Research, 2, 531-537.

Bender, T. (2011). Role Playing in Online Education: A Teaching Tool to Enhance Student Engagement and Sustained Learning. Innovate Journal of On-Line Education, 1.

Borges, V. (2014). Are ESL/EFL Software Programs Effective for Language Learning? Ilha do Desterro, No. 66, 19-73. https://doi.org/10.5007/2175-8026.2014n66p19

Brett, P. (1996). Using Multimedia: An Investigation of Learners' Attitudes. Computer Assisted Language Learning, 9, 191-212. https://doi.org/10.1080/0958822960090209

Carter, R., \& Nunan, D. (2001). The Cambridge Guide to Teaching English to Speakers of Other Languages. Cambridge: Cambridge University Press.

https://doi.org/10.1017/CBO9780511667206

Celik, S. (2013). Internet-Assisted Technologies for English Language Teaching in Turkish Universities. Computer Assisted Language Learning, 26, 468-483. https://doi.org/10.1080/09588221.2012.692385

Crystal, D. (2003). English as a Global Language. Cambridge: Cambridge University Press. https://doi.org/10.1017/CBO9780511486999

Dashtestani, R. (2014). English as a Foreign Language-Teachers' Perspectives on Implementing Online Instruction in the Iranian EFL Context. Research in Learning Technology, 
22, 1-15. https://doi.org/10.3402/rlt.v22.20142

DeFelix, J. W., Johnson, R., \& Schick, J.-A. (1990). Socio- and Psycholinguistic Considerations in Interactive Video Instruction for Limited English Proficient Students. Computers in the Schools, 7, 173-190. https://doi.org/10.1300/J025v07n01 08

Deng, H., \& Zhang, S. (2007). What Is the Effectiveness of a Multimedia Classroom? International Journal of Instructional Media, 34, 311-322.

Dewey, J. (1986). Experience and Education. The Educational Forum, 50, 241-252. https://doi.org/10.1080/00131728609335764

Diana, I. D., \& Schaik, P. V. (1993). Courseware Engineering Outlined: An Overview of Some Research Issues. Educational and Training Technology International, 30, 191-211. https://doi.org/10.1080/0954730930300302

Eizadpanah, J., Abedi, A., \& Ghaedrahmat, M. (2014). Teaching Vocabulary Electronically: Does It Work for Iranian Intermediate EFL Learners. Research Journal of English Language and Literature, 2, 16-28.

Emmerich, R. D. W., \& Devlin, D. W. (1996). Independence Day [Motion Picture]. USA: Twentieth Century Fox.

Handley, Z., \& Hamel, M.-J. (2005). Establishing a Methodology for Benchmarking Speech Synthesis for Computer-Assisted Language Learning. Language, Learning \& Technology, 9, 99-119.

Harley, B. (1996). Introduction: Vocabulary Learning and Teaching in a Second Language. Canadian Modern Language Review, 53, 3-12. https://doi.org/10.3138/cmlr.53.1.3

Hatch, E., \& Brown, C. (1995). Vocabulary, Semantics and Language Education. Cambridge: Cambridge University Press.

Jordens, P., \& Lalleman, J. (2010). Investigating Second Language Acquisition. Berlin: De Gruyter Mouton.

Kaya, T. (2006). The Effectiveness of Adaptive Computer Use for Learning Vocabulary. Flagstaff, AZ: Northern Arizona University.

Khoshnoud, K., \& Karbalaei, A. R. (2015). The Effect of Computer Assisted Language Learning (CALL) Program on Learning Vocabulary among EFL Left and Right Hemispheric Dominant Learners. European Online Journal of Natural and Social Sciences, 4, 761-777.

Krajka, J. (2003). Literature Texts and Vocabulary Help-Facilitating Reading Comprehension with Computer-Based Vocabulary Tools. The Teacher, 5, 14-19.

Krajka, J. (2007). English Language Teaching in the Internet-Assisted Environment-Issues in the Use of the WEB as a Teaching Medium. Lublin: Maria Curie-Skłodowska University Press.

Laufer, B., \& Shmueli, K. (1997). Memorizing New Words: Does Teaching Have Anything to Do with It? RELC Journal, 28, 89-108.

https://doi.org/10.1177/003368829702800106

Lee, U. (2008). Using Internet Tools as an Enhancement of C2 Teaching and Learning. Foreign Language Annals, 30, 410-427. https://doi.org/10.1111/j.1944-9720.1997.tb02363.x

Leu, D. et al. (2011). The New Literacies of Online Reading Comprehension: Expanding the Literacy and Learning Curriculum. Journal of Adolescent \& Adult Literacy International Reading Association, 55, 5-14.

Lin, P. (2014). Investigating the Validity of Internet Television as a Resource for Acquiring L2 Formulaic Sequences. System, 42, 164-176. 
https://doi.org/10.1016/j.system.2013.11.010

Lin, P., \& Siyanova-Chanturia, A. (2014). Internet Television for L2 Vocabulary Learning. In D. Nunan, \& J. Richards (Eds.), Language Learning beyond the Classroom (pp. 149-158). London: Routledge.

Liu, M. (1993). The Effect of Hypermedia Assisted Instruction on Second Language Learning through a Semantic-Network-Based Approach. Paper presented at the Annual Conference of the Eastern Educational Research Association, Clearwater, FL, 17-23 February 1993, 1-39

Lorenzo, G., \& Dziuban, C. (2006). Ensuring the Net Generation Is Net Savvy. In D. Oblinger (Ed.), EDUCAUSE Learning Initiative (pp. 1-19). EDUCAUSE.

Meagher, M. E. (1995). Learning English on the Internet. Educational Leadership, 53, 88-90.

Mollaei, F. (2013). Teachers' Perceptions of Using Technology in Teaching EFL. International Journal of Applied Linguistics \& English Literature, 2, 13-22. https://doi.org/10.7575/ijalel.v.2n.1p.13

Muehleisen, V. (1997). Projects Using the Internet in College English Classes. The Internet TESL Journal, 3, 1-7.

Peters, E., \& Webb, S. (2018). Incidental Vocabulary Acquisition through Viewing L2 Television and Factors That Affect Learning. Studies in Second Language Acquisition, 40, 551-577. https://doi.org/10.1017/S0272263117000407

Prodanovska, V. (2017). A Study of Proper Pronunciation as a Factor of Successful Communication. CBU International Conference Proceedings, 5, 778-783.

https://doi.org/10.12955/cbup.v5.1024

Radovanović, A., \& Kraguljac, V. (2017). Heading towards Internet Enhanced ESP Instruction. Zbornik radova Filozofskog fakulteta u Prištini, 2017, 145-161. https://doi.org/10.5937/ZRFFP47-14837

Read, J. (2004). Plumbing the Depths: How Should the Construct of Vocabulary Knowledge Be Defined? In P. Bogaards, \& B. Laufer (Eds.), Vocabulary in a Second Language: Selection, Acquisition, and Testing (pp. 209-227). Amsterdam/Philadelphia: John Benjamins Publishing Company. https://doi.org/10.1075/1llt.10.15rea

Rezaie, M., \& Sayadian, S. (2015). The Teachers' Perceptions of Technology Integration in EFL Classes. International Journal of English and Education, 4, 357-369.

Richards, J. C. (1976). The Role of Vocabulary Teaching. TESOL Quarterly, 10, 77-89. https://doi.org/10.2307/3585941

Sayers, D. (1993). Distance Team Teaching and Computer Learning Networks. TESOL Journal, 3, 19-23.

Schmitt, N., \& Carter, R. (2000). The Lexical Advantages of Narrow Reading for Second Language Learners. TESOL Journal, 9, 4-9.

Shin, H.-J., \& Son, J. B. (2007). EFL Teachers' Perceptions and Perspectives on Internet-Assisted Language Teaching. CALL-EJ Online, 8, 1-13.

Shokrpour, N., Mirshekari, Z., \& Moslehi, S. (2019). Learning Vocabulary Electronically: Does Computer Assisted Language Learning (CALL) Instruction Have Any Impacts on Iranian EFL Learners? Cogent Education, 6, Article ID: 1702827. https://doi.org/10.1080/2331186X.2019.1702827

Simkins, M. et al. (2002). Increasing Student Learning through Multimedia Projects. Alexandia, VA: Association for Supervision and Curriculum Development.

Sobkowiak, W. (2003). TTS in EFL CALL—Some Pedagogical Considerations. Teaching English with Technology, 3, 3-11. 
Son, J. B. (1998). Understanding Hypertext: A Discussion for TEFL. English Teaching, 53, 113-124.

Son, J. B. (2001). CALL and Vocabulary Learning: A Review. Journal of English Linguistic Science, 7, 27-35.

Stenson, N. et al. (1992). The Effectiveness of Computer-Assisted Pronunciation Training. CALICO Journal, 9, 5-19.

Sternberg, R. J. (1987). Most Vocabulary Is Learned from Context. In M. McKeown, \& M. E. Curtis (Eds.), The Nature of Vocabulary Acquisition (pp. 89-106). Hillside, NJ: Lawrence Erlbaum.

Talarposhti, A. R., \& Pourgharib, B. (2014). The Possible Effect of CALL on Vocabulary Acquisition and Instruction. Journal of Language Sciences \& Linguistics, 2, 79-84.

Tozcu, A., \& Coady, J. (2004). Successful Learning of Frequent Vocabulary through CALL also Benefits Reading Comprehension and Speed. Computer Assisted Language Learning, 17, 473-495. https://doi.org/10.1080/0958822042000319674

Tucker, J., \& Courts, B. (2010). Utilizing The Internet To Facilitate Classroom Learning. Journal of College Teaching \& Learning (TLC), 7, 37-44. https://doi.org/10.19030/tlc.v7i7.136

Verano, M. (1989). USAFA Interactive Study in Spanish. In W. F. Smith (Ed.), Modern Technology in Foreign Language Instruction (pp. 136-154). Lincolnwood, IL: National Textbook Company.

Warschauer, M. (1996). Computer Assisted Language Learning: an Introduction. In S. Fotos (Ed.), Multimedia Language Teaching. (pp. 3-20). Tokyo: Logos International.

Warschauer, M. et al. (2000). Internet for English Teaching. Alexandria, VA: TESOL.

Warschauer, M., \& Healey, D. (1998). Computers and Language Learning: An Overview. Language Teaching, 31, 57-71. https://doi.org/10.1017/S0261444800012970

Warschauer, M., \& Kern, R. (2000). Network-Based Language Teaching: Concepts and Practice. Cambridge: Cambridge University Press.

https://doi.org/10.1017/CBO9781139524735

Warschauer, M., Turbee, L., \& Roberts, B. (1996). Computer Learning Networks and Student Empowerment. System, 24, 1-14. https://doi.org/10.1016/0346-251X(95)00049-P

Webb, S., \& Rodgers, M. P. H. (2009). Vocabulary Demands of Television Programs. Language Learning, 59, 335-366. https://doi.org/10.1111/j.1467-9922.2009.00509.x

White, C., Easton, P., \& Anderson, C. (2000). Students' Perceived Value of Video in a Multimedia Language Course. Educational Media International, 37, 167-175. https://doi.org/10.1080/09523980050184736

Wilkins, D. A. (1972). Linguistics in Language Teaching. Cambridge: MFT Press.

Yoshii, M., \& Flaitz, J. (2002). Second Language Incidental Vocabulary Retention: The Effect of Text and Picture Annotation Types. CALICO Journal, 20, 33-58. https://doi.org/10.1558/cj.v20i1.33-58

Yükselir, C. (2016). EFL Instructors' and Teachers' Perceptions towards the Integration of Internet-Assisted Language Teaching into EFL Instruction. Journal on Efficiency and Responsibility in Education and Science, 9, 23-30. 